\title{
Is knowledge performative?
}

\author{
Julia Boll \\ Department of Literature, University of Konstanz, Konstanz, Germany
}

\begin{abstract}
In the summer term 2015, five academics at an interdisciplinary institution in Germany carried out the experiment of holding lectures in dialogue between a literature/theatre scholar and a scientist, on a stage, with performers and dancers. The series of four lectures explored a range of individual approaches to the subject of the experimental from the perspective of the sciences and of the theatre and outlined several conceptual overlaps between scientific content and theatre methodology. This article traces how, in addition to discussing the theoretical approaches to the subject, the lecture series also put these theories to the test and into practice by allowing performers and dancers to interfere with and even alter the lecture script. We inquired whether interdisciplinary performance lectures are feasible, whether the formation of knowledge is performative, and how this practice could be used in future conceptions of knowledge formation.
\end{abstract}

\section{KEYWORDS}

Science on stage; performance lecture; knowledge formation; conceptual integration; theatre

\section{Science/stage: an experiment in performance lectures}

'So there will always be a very small, basically negligible number of test subjects that won't behave the way we expect them to', my colleague from the natural sciences says, as he explains his standard experiment to a group of stage performers who will soon play his fruit fly larvae in a performance lecture. 'We call that number "noise".

'I'm interested in the noise', I say gleefully. I am a theatre scholar and do not have to worry about standard deviation.

My colleague gives me a long, wary look.

'Yeah, I know'.

Science/stage: an Experiment was a test run of a short series of lectures that took place over the course of the summer term 2015 at Konstanz University. ${ }^{1}$ In this experiment, the lectures were held as a dialogue between a literature/theatre scholar and a scientist, on a stage, together with performers and dancers. The four lectures explored a range of individual

\footnotetext{
CONTACT Julia Boll j.boll@uni-konstanz.de Department of Literature, University of Konstanz, Box 216, 78457

Konstanz, Germany

${ }^{1}$ I am indebted to my assistant Maximilian Heber and to Lana Daudrich for their reliable support and enthusiasm for the Science/Stage project, and to the University of Konstanz's Zukunftskolleg for facilitating it. Furthermore, my thanks go out to my five fellow lecturers, Thomas Böttcher, Giovanni Galizia, Gianluca Rastelli, Christiana Rosenberg-Ahlhaus, and Andreas Thum, who graciously and courageously took the time and energy to contribute to this project and share their expertise and experience with us.
} 
approaches to the subject of the experimental from the perspective of the sciences and the theatre.

The lectures were conceived as a trans-departmental collaborative series to explore both a subject - the intersection between the scientific experiment and the theatrical arts - and a format, that of a lecture as a dialogue between two academics from different disciplines, interacting with artists on stage: a format that aimed to capture the formation of knowledge. A further aim was to test the feasibility and applicability of such an interdisciplinary lecture project within a German university context. This exploratory project of trying out a new lecture format was as much driven by a specific research question as it was intrinsically motivated: as a literature/theatre scholar, I wanted to test whether it was possible to make an argument for the theatre as an 'enacted thought experiment'. As members of an interdisciplinary institution, we wanted to find out what would happen if we entered a stage environment and tried to cover the same, or at least adjacent, ground from two different angles, bringing performers and dancers into the mix. ${ }^{2}$

\section{Setting the stage}

The premise for this project was that lectures function analogously to live experiments, because the lecturer tries out the presentation of their material and their argument in front of a live audience. Ideally, there is a feedback loop between the lecturer and the audience. In higher education, the lecture as a teaching device can be regarded as an 'oral art', closely related to the art of storytelling, to public speeches, but also to recitations and sermons. As notably traced by Peters (2011) and in Martin Willis' recent edited collection on the topic (2016), the scientific lecture as a performance, specifically the scientific lecture including live experiments (for effect as much as for demonstration, if not more so), find their beginnings in the early nineteenth century. There is also a link to the recently popular science slams, which take their inspiration from the performance competition form of poetry slams, where poets compete against each other with original work and the audience votes on who wins. In the case of science slams, scientists compete by describing their research project in a crowd-pleasing way to a non-expert audience; they are judged for the performance of their presentation as much as for the content and hence, for their project. The performance lecture therefore sits on the fence between a traditional lecture and a format that, in an academic context, is mostly associated with activities of public outreach and science communication. In the 2013-2014 double issue of Interdisciplinary Science Review, Brian Schwartz reports on the Science \& the Arts Series (20002013), CUNY's successful NSF-funded outreach programme that served to communicate science to the general public and promoted the use of theatre and performing arts in science education. The series also made use of the significant number of plays that take science as their subject (Schwartz 2014). In her 2006 study of these dramatic plays on science, Kirsten Shepherd-Barr points out that science plays of the early 2000s started linking performance techniques and science in innovative ways and blurred the lines between play and scientific lecture (Shepherd-Barr 2006, 199).

${ }^{2}$ The Zukunftskolleg is an interdisciplinary institute of advanced studies at the University of Konstanz. Fellows come from the STEM disciplines, social sciences, and the humanities. 
By giving our performance lectures in dialogic form, we not only introduced a theatre convention to the format, but we could actively debate the different ways in which the scientific approaches and those from a literature/theatre perspective overlap and intersect, creating the lectures as live experiments, using the space of the stage as a space for experimentation - a laboratory. The dialogue and interaction between two academics from different disciplines, and the scripted yet unpredictable element of introducing performers and dancers to the lecture, necessitated a certain 'leap of faith'. mainly on the part of the scientists less familiar with the dynamics of theatrical group improvisation and the apparent loss of full control over (the presentation of) one's material. The set-up of these lectures thus reflected the subjects they explored: the nature of the experiment, the questions of evidence and predictability, of knowledge and control.

The experiment consisted of four lectures. Before the actual phase of lecture preparation and subsequent performances, there were several preliminary meetings with each of the scientists, during which we identified possible aspects of their research that might be suited for this format and discussed the conceptual overlaps between their research questions and what I was looking for in the performance. Once funding was secured (mainly to be able to pay the performers), we started recruiting performers, primarily drawing on the university's student base. At two recruitment meetings, we welcomed 30 interested students and some junior staff members from across all disciplines, though, intriguingly, the largest group came from physics.

After a half-day stage workshop for the performers, led by a theatre practitioner, there were several consecutive meetings for each lecture: a first encounter consisted of the scientist, the performers, and me. The scientist explained their work to us, I laid out some initial conceptual ideas pertaining to possible staging and performance narratives, then we let the performers brainstorm possible approaches to the material and what a performance lecture on, say, biochemistry could look like. The first experience the performers had within the project was thus an unexpected handover of control to them: we encouraged a collaborative creative approach coming from the group, while the lecturers mainly just gave an overview of their research and filled in details when the performers needed clarification. The performers - most of them amateurs, though a few had had previous experience with improvisational theatre or had been part of a stage production - quickly took to the concept and came up with an abundance of ideas.

The scientist and I then met again to co-write a preliminary lecture script which was sent out to the performers so they could familiarize themselves with a rough 'roadmap' to the respective lecture. The next meeting was a first practical workshop with performers and lecturers together, including warm-up exercises and a practical exploration of the lecture material ('walk-through'). This step ties in with John Dewey's principles of experiential learning, as it opens up a space for the participants to explore imaginatively and physically the mostly unfamiliar material. Dewey's influence on educational practices, especially with regard to the connection between art and a contemporary liberal education, has been well established both by Nicholson (2009) and Nancy Kindelan, who traces his theory of learning based on a 'theory of experience' and argues experiential learning is fundamental to an education for social intelligence (Kindelan 2012, 107). In Art as Experience, Dewey reasons there is a connection between art and its aesthetic experience that can become formative: 
Experience in the degree in which it is experience is heightened vitality. Instead of signifying being shut up within one's own private feelings and sensations, it signifies active and alert commerce with the world; at its height it signifies complete interpenetration of self and the world of objects and events. (Dewey [1938] 1958, 19)

The performers - and by degrees the lecturers - truly experienced an interpenetration of themselves and the material they embodied over the lecture series. In her study on theatre's place in a contemporary liberal education, Kindelan makes a strong case for the academic and practical methods of the theatrical arts - and the studying thereof - as potentially groundbreaking if integrated across subjects into the general higher education curriculum. Stating that ' $[t]$ heatre's modes of inquiry, imagistic language, and signature pedagogy provide the critical skills as well as the actual, virtual, and vicarious experiences through which students can enrich their ability to perceive such connections to self and to others'. Kindelan suggests naming the continuity between art and experience, as defined by Dewey, 'artistic literacy' (Kindelan 2012, 108).

For the Science/Stage lecture series, this experiential collaborative process of 'walking through' the material, borrowed from devised theatre, during which the performers' input formed the backbone of what would first become the lecture script and later the lecture performance, was vital both for the development of the lecture and the process of learning and creation. Discussing the Deweyan principles of experiential learning, Nicholson stresses that "[a] script is not, of course, a fixed blue-print for performance but a starting-point for another set of interpretations, and the "gap" between page and stage needs to be filled by the imagination' (Nicholson 2009, 53). Throughout the lecture series, the performers and the lecturers were constantly reworking the script. After the first physical exploration of the material, the initial script was revised and keywords were included for the performers to ensure they would know at which part in the lecture they were supposed to change track, to launch into a different routine, or otherwise react to the spoken-word content. Ideally, the next meeting was already the dress rehearsal before the actual performance - though this did not always work out as planned. The lecture on quantum physics needed more than one devising workshop before the dress rehearsal: due to the more abstract nature of the material, the gap to be bridged between page and stage was perceived as wider than in the previous lectures. The 'dance lecture' also required a different level of preparation from the dancers - though the two spoken-word lecturers were not present for most of the dance rehearsals.

For the whole series of four lectures, there were 28 preparatory meetings before the actual performances. This does not include the number of extra meetings I had with my assistant, or with university administration to be schooled in fire safety training (for use of the university's studio stage), to try and secure access to the studio stage, and to negotiate the student performers' formal assessment. Between my assistant and myself, we had a turnover of about 1,000 emails between January and July 2015, just pertaining to this project. The project was conceived at a university without a full theatre/performance department, so without the proper infrastructure necessary: the university's studio stage was only sporadically available for this project and after trying negotiation; to date, there are no standing stage management and lighting/tech crew, no general choreographer or stage coach as part of a permanent team. The initial stage training for most of the performers was provided either during the workshop with the theatre practitioner or by myself. The sheer amount of time needed for the conception and management of even 
just four lectures matches Kindelan's assessment of theatre productions in education: while they are high gain, they are also time-consuming and labour-intensive and therefore costly (Kindelan 2012, 102).

\section{Kidnapping lecturers}

The first lecture featured my colleague Thomas Böttcher, a biochemist, and myself. It was called 'Is That Your Microbiome Trying to Take Over?' and given in May 2015. Böttcher leads a biochemistry research group working on natural product discovery, with a particular interest in microbiomes and the social behaviour of bacteria. ${ }^{3}$ Amongst other things, the group is identifying antibiotics against which our microbiomes are not yet resistant. In this lecture, we studied the meta-level of experimental thought by investigating what would happen if we could observe our own microorganisms staging a hostile takeover.

This first was our shortest lecture, lasting about 20 minutes. We had eight performers on stage - and 'stage' here denotes a large university seminar room. Böttcher and I gave this lecture in actual dialogue, while the performers moved around us as our respective microbiomes, at times merging, at times working against each other, then developing resistance against antibiotics, plotting against us and kidnapping one lecturer off the stage.

The lecture functioned as a demonstration of the researcher as the actual body of evidence: their findings are evident not only by the experimental proof they provide in their work as a scientist. In a classical lecture on his research, Böttcher would have shown images and microscopic recordings, and he would have talked the audience through formulas and cited other researchers' evidence. However, in every lecture, and especially in this performance lecture, his findings are also evident because the audience can watch him 'live' as he thinks through his arguments, demonstrates how he connects his findings, and comes to his conclusions. A lecture is therefore always a performance of thinking, and the lecturer becomes the subject (Peters 2011, 53). As lecturers, we demonstrate how we think; we can be observed, tested, dissected, put back together (61; also Boll and Böttcher 2015).

The point of a lecture is that it happens in front of an audience. Consequently, we immediately dropped theatre's famous fourth wall for the performances: both lecturers fully acknowledged that the audience was in the room, that they were not only speaking to each other but also to an audience. This served as a demonstration of the double reality of the theatrical space: the performers are there as performers, but also, defined by the rules of the stage, as the microbiomes surrounding the two lecturers.

The format of this lecture was structured in classic question-and-answer style: the theatre scholar asked questions of the biochemist and thus played both the host for the lecture and the inquiring mind, allowing the biochemist to demonstrate knowledge. Accordingly, we first established the traditional power hierarchy between the 'master' of knowledge and the 'so-called ignorant pupil', a dynamic explored by Jacques Rancière in his reflections on 'the ignorant schoolmaster' (1991) and then revisited and revised in his 2007 essay 'The Emancipated Spectator', in which he proposes to consider knowledge transfer from a principle of intellectual emancipation, which he suggests to

${ }^{3}$ Emmy Noether Group 'Biological Chemistry Research Group', based at the University of Konstanz. Böttcher is PI. 
understand as a development starting from 'the process of verification of the equality of intelligence' (Rancière 2007, 275). Drawing on his own earlier work on how to bridge the knowledge-gap between schoolmaster and pupil, Rancière applies the concept to the knowledge-gap between performer and spectator and defines the collective power of spectators as one of 'translating in their own way what they are looking at ... an unpredictable and irreducible play of associations and dissociations' (279).

In the lecture on microbiomes, we witnessed the performers themselves take charge of the material as a collective and ultimately just altering the script by themselves. We started out by using them to illustrate the research, until they started exploring its implications. When, near the end of the lecture, the biologist admits that it is well possible to be taken over by one's microorganism, which, to a certain extent, might even operate independently, the theatre scholar attempts to continue the lecture by raising questions of agency and identity, but is soon overwhelmed and abducted from the stage by her microbiome. Though briefly discussed in rehearsal, this particular sequence at the lecture's end played out in a largely improvised way during the actual performance, mainly facilitated by the performers having grown stage-confident enough (and comfortable enough with physical proximity to each other and the lecturers) to jostle me around while I was talking and finally manhandling me out of the room.

The audience for this first lecture was formed largely by our colleagues from the interdisciplinary institute and associated academic staff. A smaller group consisted of students with a connection to the performers (friends or partners). As we had declared everybody inside the theatre space, including the two lecturers and the audience, a part of the experiment, we had a question and answer session with the audience afterwards. This revealed a lot of curiosity and interest in the project, but also some misunderstanding as to its implications, and what audience the format would largely be aimed at; the initial assumption being that it would be 'for children', because the lecture represented scientific content in a humorous way, and because the microbes, as depicted by the performers, were to a certain extent anthropomorphized. Great interest was taken in the production and rehearsal process: the information that there had actually only been two proper rehearsals prompted some astonishment. Several members of this first audience cohort would prove to come to every subsequent lecture and would later remark on how the lectures grew more and more complex and polished.

\section{Talking to larvae}

The second lecture, called 'Rewriting the Experimental Script', also took place in May 2015 and featured neurobiologist Andreas Thum and myself. Thum leads a research group, ${ }^{4}$ which studies the brain of the fruit fly larva in order to trace learning processes in a very simple brain. It was our first lecture on the university studio stage.

In this lecture, we discussed the nature of the scientific experiment and how a wilful larva's deviation from the script leads to interesting questions about the predictability and reliability of a standard experiment. We also explored the parallels between preparing and then conducting a scientific experiment and preparing for and then performing a ${ }^{4}$ Emmy Noether Group 'Neuronal, molecular and behavioral basis of learning and memory in Drosophila larvae', based at
the University of Konstanz. Thum is PI. 
piece of live art. Kindelan points out that theatrical productions are always based on research, on 'background analysis of social and cultural history as well as human psychology', and that

theatre's modes of inquiry share in the research methodologies of the academy. In addition, the theatre's investigative procedures include the integration of cross-disciplinary connections and the collaborative exchange of information and ideas among faculty mentors and student peers. The production of a play, which is seen as an artistic 'experiment' (similar to experiments in the science lab), allows the student/artist/researcher to continue to observe and analyse causal relationships, to formulate and test hypotheses, to draw some conclusions about social issues and human psychology and, eventually, to evaluate the 'results' of the artistic experiment. (This is why theatre educators often call their small black-box theatres 'lab' or 'experimental' theatres). (Kindelan 2012, 100)

To underline the idea of the lab, we constructed a petri dish from packaging paper on stage, as the frame of this lecture was to recreate one of Thum's standard experiments: the fruit fly larvae are trained to associate a certain odour with a specific reward. Their response to the odour is then tested without the reward present: a classic Pavlovian conditioning experiment. While we ran the experiment, I introduced the audience to the special contract between actors and spectators that makes theatre possible, the agreement that what happens on stage is real within the confines of the stage, that the performers on stage, even though clearly human, were also the larvae in Thum's experiment, and that I, though clearly a theatre scholar acting as host for the lecture performance, was also Thum's lab assistant, complete with white lab coat and clipboard. This cognitive ability to create a world in the subjunctive, in the 'as if, by deliberately blending reality with the dramatic world and 'a living person [the actor or performer] with an identity' has been termed conceptual blending or conceptual integration by Gilles Fauconnier and Mark Turner. They point out that in each particular theatrical representation, there will be rich shared generic structure between "reality" and "fiction"" (Fauconnier and Turner [2002] 2003, 266). Bruce McConachie remarks on conceptual integration as depending 'on our ability to think with concepts' (McConachie 2013, 20). In a rebuke of the popular assumption that the success of a dramatic production relies on whether the audience 'believes' what is shown on stage, he stresses that '[e]ngaging with actors playing characters on the stage involves conceptual integration, not poetic faith. Spectators combine their mental concepts of a specific actor with a specific character to create blended actors/characters' (52).

As a topic that carried over from the previous lecture, we used this lecture to introduce the concept to the audience during the experiment. The audience was asked to add several layers to this first level of conceptual integration when the seven performers gradually strayed from the standard script. At first, they behaved according to how Thum's fruit fly larvae would when the experiment is conducted in his lab. However, we then deviated from the standard experiment by creating an interview situation, during which the scientist Thum had the opportunity to ask the larvae about their reasons for choosing a specific odour over another. This is how the noise-conversation referred to at the beginning of this article found its resolution: Thum might well have been indulging my penchant for investigating noise, but there was also a genuine wish, obviously impossible to fulfil in the real, offstage lab situation, to be able to 'just ask the larvae' why they behaved in a certain way, because the actual object of inquiry is so tiny even microscopic observation of the live 
larvae is not always entirely conclusive as to what, precisely, it is they are doing. Again, we left it to the performers to choose how to react to the researcher's queries. They openly played with a question much discussed in the preparatory meetings - whether the larvae are sentient - by referring specifically to the above-mentioned conceptual integration, as they were, in the staged interview, foregrounding their double identity as human performers enacting fictional larvae. The experiment came to an end when the 'larvae' pupated (Boll and Thum 2015).

\section{Walking through walls}

'Schroedinger's Stage', the third lecture, featured theoretical physicist Gianluca Rastelli and myself. It took place in June 2015. Rastelli's research in quantum physics focuses on the crossover between the quantum realm and the macroscopic world. ${ }^{5}$ In this lecture, which was approaching 40 minutes, we discussed the concepts of observability and non-observability of quantum space by exploring whether the theatre allows for a person to be here and there, visible and invisible, dead and alive at the same time. Of the four lectures, this was the one relying most prominently on both lecturers' scholarship, as both of us drew heavily on the history of our disciplines and strove to find examples that would demonstrate conceptual overlaps. Instead of being dialogic, it contained two strands of lectures interweaving and being interconnected by the performers' action. Rastelli gave an overview on quantum physics; I gave a lecture on visibility, invisibility, the dead on stage, and on theories of quantum physics in relation to theatre theory. Meanwhile, five performers interpreted concepts such as particle/wave duality, quantum superposition, quantum suicide, and spooky action between entangled states. There was little interaction between the lecturers and the performers and we used a rather formal aesthetic: throughout most of the lecture, the two lecturers remained quite static, positioned downstage centre left and centre right respectively, while the performers occupied centre stage and upstage.

In the previous lectures, we acknowledged we were speaking to a lay audience and therefore avoided delving too deeply into conceptual questions. This lecture's theoretical content was much more pronounced, because to come to the practical exploration of quantum mechanics, we first needed to establish some theoretical foundations. In order to demonstrate the conceptual overlaps between quantum mechanics and theatrical practice, I lead the audience through examples from theatre history and introduced them to how a theatre scholar would read and analyse these examples in relation to the concepts outlined by my colleague.

I introduced Russian Jewish playwright S. Ansky's 1920 play The Dybbuk, or Between Two Worlds. Set in a Shtetl in Volhynia near the end of the nineteenth century, the play tells the story of a young woman possessed by the dislocated soul of the young man she had meant to marry but who died when he learned she was to marry somebody else (Ansky 1971). The play can be genuinely frightening, mostly due to its uncompromising insistence that the demon is real, that there actually is a ghost on stage. I used it as an entry point to discuss why the theatre is interested in and interesting for the concept of liminal stages such as the one between life and death, arguing that the ephemeral nature of live

${ }^{51}$ Quantum Transport and Interactions in Nano-Electronic Systems', based at the University of Konstanz. Rastelli is PI. 
performance coupled with the idea of the theatre as a self-contained lab somewhat disconnected from reality allows for a heightened sensitivity towards what cannot be fully observed or replicated in the 'real world'. As theatre historian Andrew Sofer states,

something hidden is disclosed [on stage], even as it eludes our sights. Whether hallucinated demons, offstage sexual or violent acts, self-consuming protagonists, invisible surveillance, or contemporary trauma, theatre conjures the unseen in the service of its imaginative poetics. (Sofer 2013, 145)

Upon entering a theatrical space, both spectators and performers are willing to accept certain rules of reality have been suspended, that what is presented on the stage is not 'real' in the same way it would be without the theatrical framework. Yet, as introduced earlier, the process of conceptual integration allows the audience to accept the becoming-reality within the space of the stage, to accept things to be observable on stage that cannot be observed 'in life'. We watch a young woman possessed by a demon on stage, and whether we believe in demonic possession in the reality outside the theatre or not may influence whether Ansky's play might actually frighten us, but not whether we do or do not believe that Leah, the figure, is actually possessed by the demon. For this play, it has been established that the demon is there - and so it is present, for us, at the theatre (Boll and Rastelli 2015).

The hypothesis of this lecture was that theatre offers an unobservable space, which, when speaking about quantum mechanics, Rastelli defines as follows:

In a typical quantum phenomenon [...] we can consider three actors: (1) the system to be analysed (the object), (2) the scientist with their apparatus for measurement (the observer), and (3) the rest of the world. In order to probe the intrinsic properties of a system, for instance a single atom, we have to disconnect it from the rest of the world. Therefore, in a first step we prefer to exclude the third actor; ideally, we would like to disconnect or separate the atom from the rest. You have to imagine putting an atom into a black box with nothing else inside: no lights, no other atoms or objects with which it can interact. You can think of this atom as in a kind of 'limbo' dark space. At the time $t$ equals to zero, even the observer does not see the system. (Boll and Rastelli 2015)

We suggested to the audience to regard the space behind the two lecturers as an unobservable space - unobservable to the two lecturers, that is, but not to the audience. Thus, the lecture allowed the audience to 'observe' a quantum phenomenon after all: when the performers illustrated how an atom moves as a wave in space while it is unobserved (whereas it will be fixed in one position the moment it is observed), they were 'here and there' at the same time, in the reality inhabited by the two lecturers. 'According to quantum mechanics', Rastelli says, 'the observation or the observer affects the reality, or, equivalently, the reality is defined only by how we can observe it' (Boll and Rastelli 2015). When Rastelli turned around to look at the performers, they froze on the spot. When the observation 'stopped' because Rastelli turned back to the audience to continue explaining this phenomenon of particle-wave duality, they started to move again.

I then spoke about Polish theatre maker Tadeusz Kantor's 1985 production Let the Artists Die. The play marks the horrors of twentieth-century Polish history, but it is also one man's private, surrealist nightmare. Kantor features on the stage in four different incarnations: the man himself is conducting the proceedings from the side of the stage, but in full view of the audience, but he also appears within the play three times, at various ages, 
as both fictional and 'real'. Rastelli linked this overlapping of the simultaneous existence of one man in four different realities at different stages of his life to the theory of the multiple-worlds reality, to the concept of quantum superposition and, by extension, to the theory of quantum suicide, which was represented by our performers on the stage.

The example of this third lecture shows that throughout the whole series theatre was not used as an illustration of the theory, in this case of quantum mechanics. The series therefore differs to what Shepherd-Barr has described as practice in scripted dramatic science plays, where a particular scientific idea or concept is employed 'as an extended theatrical metaphor' (Shepherd-Barr 2006, 201). What could be observed was a correlation of the theory and theatrical practices, as Andrew Sofer traces in his study on invisibility on stage. Sofer speaks about the moments in theatre when a character is offstage, for example, between scenes, to argue that

an invisible character simply has no precise location or trajectory when unobserved. Like a subatomic particle, the unseen character can be 'everywhere at once', until the very act of observation pins him or her down. An unobserved fictional character can be in different states of being simultaneously, not unlike a quantized particle. A quantized character becomes a sum of probabilities rather than a history. (Sofer 2013, 40, emphasis in the original)

I argue that, by extension, what we can see on stage is not only a representation of (one version of) reality, but also of possibility and potentiality, and easily of several at the same time. To acknowledge the theatre's ability to create and present what we can imagine, in contrast to what we can observe, is in true spirit of avant-garde dramatist Antonin Artaud's call for a theatre that represents 'everything in love, crime, war and madness' (Artaud 1970, 65) and his declaration that theatre 'can only happen the moment the inconceivable really begins' (18), maintaining that it has to access the audience's dreams and nightmares and present them not as make-believe, not as imaginary, but as something real, as if the interior landscape of our minds were made visible on stage.

\section{Dancing with bees}

The fourth and final lecture, 'The Dancing Bee', took place in July 2015 and featured Giovanni Galizia and myself. Galizia is a biologist and zoologist working on bees, specifically on how they communicate via odour. ${ }^{6}$ We were joined by sports lecturer Christiana Rosenberg-Ahlhaus, who leads the University's dance troupe and whose dancers were part of the lecture. It consisted of three lectures in one: one given by the biologist, one by the literature/theatre scholar, and one by the dancers. In this lecture, we explored the connections between the bees' communication by odour and dance and human dance performance.

Galizia introduced the elements of beehive communication via odour and dance, and I traced the development of dance as the oldest form of group communication from ritual to art by explaining the concept of ritual and its relevance to performance studies and performance practice. The performers, who had been improvising on the themes of odour and pheromones, launched into a ritualistic performance, touched on swarm behaviour

\footnotetext{
${ }^{6}$ The 'Research Group in Insect Olfaction' is based at the University of Konstanz. Galizia is Group Leader and Professor of
} Neuroscience and Zoology in the Department of Biology. 
in an echo of the first lecture of the series, and finally commented on the ephemerality of both the theatrical performance and the globally disappearing bee tribes by slowly fading from the stage. The aim of this lecture was to establish a connection between the honeybee hive, the head (via linking theatrical performances to thought experiments), and the theatre as a space for community forging through ritual and communication by dance. In this lecture, we explored the concept of performativity most extensively - the quality of an identity being created and sustained by repeated performance - by experimenting with how performances create communities and with the communal reaction to the information flow between performers and spectators (Boll, Galizia, and Rosenberg-Ahlhaus 2015).

This lecture returned to several ideas raised in the previous lectures, notably that of conceptual blending and the notion that the theatre does not primarily serve as a space where reality is represented or where 'more complex' material is illustrated, let alone simplified. It should also be understood as a space for what could be called embodied thought experiments, where a society considers itself and questions its self-perception in a public space, where concepts and problems can be observed and contemplated under 'contained' conditions in a way that is not always possible in life.

\section{Creating and educating}

By recognizing themselves as part of the experiment, the lecture audiences were enabled to reach a stage of creative transfer of knowledge that has been called 'deep learning'. This concept builds on Benjamin Bloom's Taxonomy of Educational Objectives and is reached when the learner starts to evaluate the knowledge they have gained and creatively apply it:

Create involves putting elements together to form a coherent or functional whole. Objectives classified as Create have students make a new product by mentally reorganizing some elements or parts into a pattern or structure not clearly present before. [...] To the extent that deep understanding is an act of construction or insight, the cognitive processes of Create are involved. (Anderson et al. 2001, 85, emphasis in the original)

This also holds true for the performers. The particular format chosen allowed them to interfere with and even alter the lecture script. By testing out in practice how the theatre can be used to think through notions of the experimental, we could reassess our conception of scientific facts and scientific evidence, the notion of predictability, and who or what is actually part of the experiment. Ultimately, we explored whether, through experiential learning, knowledge is performative, whether the formation of knowledge is performative, and whether the dissemination of knowledge is performative.

Several participants handed in self-reflective essays after the series ended. I am drawing on some of these to state that most of the students were drawn to the project because they simply could not imagine how science and acting or dancing might fit together. They highly appreciated being allowed to experiment freely with the material, develop creative approaches to making the knowledge their own, and disseminating it. There is also proof of a remarkable intake of specialist knowledge, considering that most of the participants came from different subjects and often had little to no familiarity with the subject matter that was being presented in the individual lectures, and that they only spent a 
comparatively short time being introduced to the material. The embodied experience of how swarm behaviour develops, for example (lecture 1), was something that several participants stated they could never properly imagine until they tried it out themselves.

For the lecture series' pedagogical approach of experiential learning to develop skills in critical analysis and for the academic concept of practical exploration to achieve theoretical results, I drew heavily from Nancy Kindelan's Artistic Literacy and Robin Nelson's Practice as Research in the Arts. Coming from a theatre and drama education perspective, Kindelan explores how undergraduate theatre programmes can play a significant role in accomplishing the aims and learning outcomes of a contemporary liberal education. She argues that 'theatre's signature pedagogy' - which she describes as a 'triad of traditional scholarship: dramatic theory, history and literature' (Kindelan 2012, 94) - helps students acquire the transferable skill set that makes up the liberal education framework:

inquiry skills (the ability to think abstractly, analytically, and critically), literacy skills (the ability to communicate clearly and manage information), ethical and value skills (an awareness of humanistic and social problems), self-motivational skills (the capability to synthesise ideas and to apply that understanding to the development of a final project or paper), teamwork and problem-solving skills (the flexibility to appreciate multiple perceptions when confronting issues), creative skills (the capacity to image and reimage perceptions about life's complexities), and lifelong learning skills (potential to reuse these skills as enrichment tools throughout life). (77-78)

Kindelan argues that a student's involvement in the production process of a play renders their relationship to the theatrical event 'more tangible or immediate and, thus, more memorable' (Kindelan 2012, 84). Her assessment that even theoretical material or content that students may initially have deemed to be 'too theoretical or too removed' tends to become difficult to dismiss or forget, because the students' relationship to the material has become more immediate (85), could also be experienced in the context of the Science/Stage lecture series. Theatre activities help learners develop artistic literacy, Kindelan says, and the cultivation of a 'critical ability to comprehend and interpret the world of the play script through the intensive experience of viewing or creating the theatrical event' (88) could be observed in the performers' intellectual and creative reorganizing and processing of the scientific content during the workshop phase of the individual lectures. When engaging with the scientific material or concept in the first meeting with the scientist and then in the practical workshop, the performers displayed a high level of creative and critical thinking, of interdisciplinary communication skills, and a remarkably quickly developed familiarity with the material, to the point of dauntlessly and radically reshaping it for performance purposes. The lecturers partaking in these interdisciplinary performance lectures experienced a similar process. Apart from learning about each other's research methods, one important factor turned out to be the selfacknowledgement of the lecturer's presence, as a person, in the performance lecture, and by implication, in all lectures.

Speaking of practice as research, Robin Nelson stresses that in the whole field, '[a] key issue is whether insightful thought might be engaged materially as well as abstractly "in the mind"' (20). He prefers to speak of knowing instead of knowledge, because

the noun 'knowledge' might suggest a clearly bounded object of knowledge separate, and at a distance from, an observing subject and available to be seen-known across time and space by 
other viewing subjects. The verb (present participle) 'knowing' in contrast acknowledges a subject engaged in the act indicated and perhaps engaged in a processual relationship spatially more proximal to the object to be understood. [...] [T] he attempt to make tacit knowledge more explicit involves a process of dynamic movement from the closeness of subjectivity to a greater distance, if not quite achieving objectivity as traditionally conceived. (Nelson 2013, 20)

This is a strong argument towards considering knowledge and its formation as 'a doing' in Austin's sense of the word - instead of knowledge as an abstract object one 'acquires'. In fundamental difference to other models of knowledge dissemination by performance, notably science slams, this series relied on collaborative devising as a method of allowing the performers and lecturers to embody the material, make it their own, and create something new with it. The series shares some conceptual ground with what Shepherd-Barr calls 'alternative' science plays', rooted in actor-director-based work, where 'the theatrical production derives from a collection of ideas, a set of writings that serve as a springboard for further workshopping, rather than a fixed and final, stable, and authoritative script that is simply to be acted' (Shepherd-Barr 2006, 202).

For all the academics involved, the lecture series offered an important opportunity to test new pathways in teaching in higher education and explore educational collaboration in a fresh, more direct way. The four scientists agreed to partake in the performance lecture series out of a profound curiosity about what it would be like to work so radically across disciplines and against expectations, to follow an invitation to let things 'run wild' and trust the performers to find their way through the material, to experience how theatre works and how it would work with their research. Potentially, this format could be adapted to any scientific or other research content. Of course, when aiming for a specific impact within the academic environment, there is a special gain to be had from putting, say, quantum physics on stage, because even though far from unusual, this is always assumed to be the most unlikely and daring endeavour. As an experiment in trans-departmental collaboration, this project also served as an opportunity to highlight what theatre and performance studies can do, what they could bring to an integrated approach to research and teaching in higher education. It therefore also reflected how an active turn towards trans-disciplinarity could significantly strengthen the communication of knowledge in view of recent developments in higher education practices. However, in order for theatre and performance studies not to be relegated to merely play 'handmaiden' to the sciences in displays of public outreach, it is vital that future projects continue to uphold what may be regarded as one of the defining characteristic of humanities research that we keep looking for and prodding at the noise.

\section{Notes on contributor}

Julia Boll holds a doctorate in drama from the University of Edinburgh. She was a director of the Scottish Universities' International Summer School, a teaching assistant at Edinburgh, and worked for the Edinburgh Review. In 2013, she joined the University of Konstanz to research the representation of the bare life on stage, a project for which, as PI, she has received funding from the German Research Foundation. Since 2012, she has been a member of the multi-disciplinary research project Fiction Meets Science (Universities of Bremen and Oldenburg). Her monograph The New War Plays was published by Palgrave Macmillan in 2013. 


\section{Disclosure statement}

No potential conflict of interest was reported by the author.

\section{References}

Anderson, Lorin W., David R. Krathwohl, Peter W. Airasian, Kathleen A. Cruikshank, Richard E. Mayer, Paul R. Pintrich, James Raths, and Merlin C. Wittrock. 2001. A Taxonomy for Learning, Teaching, and Assessing. A Revision of Bloom's Taxonomy of Educational Objectives. Abridged Edition. New York: Longman.

Ansky, S. 1971. The Dybbuk. A Play in Four Acts. 1926. Translated by Henry G. Alsberg and Winifred Katzin. New York: Liveright.

Artaud, Antonin. 1970. The Theatre and its Double. 1938. Montreuil: Calder.

Boll, Julia, and Thomas Böttcher. 2015. "Is That Your Microbiome Taking Over?" Science/Stage Lecture Series, May 19, University of Konstanz, Germany. Accessed 15, 2016. https:// streaming.uni-konstanz.de/talks-events/zukunftskolleg/performance-lecture/is-that-yourmicrobiome-trying-to-take-over/.

Boll, Julia, Giovanni Galizia, and Christiana Rosenberg-Ahlhaus. 2015. “The Dancing Bee.” Science/ Stage Lecture Series, July 16, University of Konstanz, Germany. Accessed July 15, 2016. https:// streaming.uni-konstanz.de/talks-events/zukunftskolleg/performance-lecture/the-dancing-bee/.

Boll, Julia, and Gianluca Rastelli. 2015. "Schroedinger's Stage." Science/Stage Lecture Series, June 26, University of Konstanz, Germany. Accessed July 15, 2016. https://streaming.uni-konstanz.de/ talks-events/zukunftskolleg/performance-lecture/schroedinger-s-stage/.

Boll, Julia, and Andreas Thum. 2015. "Rewriting the Experimental Script." Science/Stage Lecture Series, June 26, University of Konstanz, Germany. Accessed July 15, 2016. https://streaming. uni-konstanz.de/talks-events/zukunftskolleg/performance-lecture/rewriting-the-experimentalscript/.

Dewey, John. (1938) 1958. Art as Experience. New York: Capricorn Books.

Fauconnier, Gilles, and Mark Turner. (2002) 2003. The Way We Think. Conceptual Blending and the Mind's Hidden Complexities. New York: Basic Books.

Kantor, Tadeusz. 1985. Niech sczezna artyšci (Let the Artists Die). Perf. Teatr Cricot 2. Recording of the performance at the Juliusz Słowacki Theatre in Krakow, January 1986. Film dir. Stansilaw Zajaczkowski. Cricoteka, 2008.

Kindelan, Nancy. 2012. Artistic Literacy. Theatre Studies and a Contemporary Liberal Education. New York: Palgrave Macmillan.

McConachie, Bruce. 2013. Theatre \& Mind. Houndmills: Palgrave Macmillan.

Nelson, Robin. 2013. Practice as Research in the Arts. Principles, Protocols, Pedagogies, Resistances. Edited by Robin Nelson. Houndmills: Palgrave Macmillan.

Nicholson, Helen. 2009. Theatre \& Education. Houndmills: Palgrave Macmillan.

Peters, Sibylle. 2011. Der Vortrag Als Performance. Bielefeld: transcript.

Rancière, Jacques. 1991. The Ignorant Schoolmaster. Five Lessons in Intellectual Emancipation. Translated and introduced by Kristin Ross. Stanford: Stanford University Press.

Rancière, Jacques. 2007. "The Emancipated Spectator." Keynote Address at the 5th International Summer Academy of the Arts, 20 August 2004, in Frankfurt am Main, Germany. First published in Artforum 2007, 270-281.

Schwartz, Brian. 2014. "Communicating Science through the Performing Arts." Interdisciplinary Science Reviews 39 (3): 275-289. Accessed February 23, 2017. http://www.tandfonline.com/ doi/full/10.1179/0308018814Z.00000000089.

Shepherd-Barr, Kirsten. 2006. Science on Stage. From Doctor Faustus to Copenhagen. Princeton: Princeton University Press.

Sofer, Andrew. 2013. Dark Matter. Invisibility in Drama, Theater, and Performance. Ann Arbor: University of Michigan Press.

Willis, Martin, ed. 2016. Staging Science. Scientific Performance on Street, Stage and Screen. Houndmills: Palgrave Macmillan. 